\title{
Effects of a Single Session Group Intervention for Pain Management in Chronic Pain Patients: A Pilot Study
}

Ted Jones · Samantha Lookatch · Todd Moore

To view enhanced content go to www.paintherapy-open.com

Received: February 25, 2013/ Published online: April 30, 2013

(c) The Author(s) 2013. This article is published with open access at Springerlink.com

\begin{abstract}
Introduction: Behavioral and psychological interventions are key components of treating chronic pain. However, there are logistical barriers to providing such treatments, including a lack of psychological staff to provide such interventions and limited ability of patients with chronic pain to attend multiple sessions. As other areas of mental health have shown promise in providing single session interventions for various conditions, this pilot study hypothesized that a single group session for chronic pain patients could be helpful in decreasing patient pain catastrophizing. The five content areas addressed in the group were
\end{abstract}

T. Jones $(\bowtie)$

Behavioral Medicine Institute, Pain Consultants of East Tennessee, 1128 E. Weisgarber Road, Suite 100, Knoxville, TN 37909, USA

e-mail: tjones@painconsultants.com

S. Lookatch · T. Moore

University of Tennessee, Knoxville, TN, USA

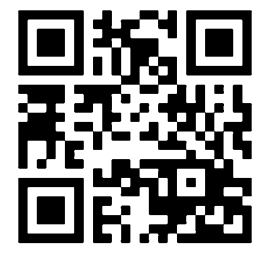

Enhanced content for this article is

available on the journal web site:

www.paintherapy-open.com termed understanding, accepting, calming, balancing, and coping.

Methods: A pilot study was undertaken. Chronic pain patients were given a pre-group assessment, including the Pain Catastrophizing Scale with a follow-up assessment administered 3 months later.

Results: Fifty-three patients were studied. Results showed a significant decrease in overall pain catastrophizing scores at follow-up. A clear majority of patients also reported that the group was helpful and should be offered to other pain patients.

Conclusion: This study suggests that a single session group can be a helpful intervention for patients with chronic pain.

Keywords: Catastrophizing; Chronic pain; Group therapy; Pain Catastrophizing Scale; Single session

\section{INTRODUCTION}

Chronic pain has become a major public health problem in the US, affecting approximately 100 million persons at an annual cost of over 500 billion dollars in direct medical costs and lost income [1]. In a recent review of this problem, 
the Institute of Medicine (IOM) reported that there are significant barriers and needs for improvement in the treatment of chronic pain. One recommendation of the IOM was that the pain treatment field promotes and enables self-management for patients with chronic pain, as this is an important aspect of overall pain treatment [1]. In addition to interventional treatments (surgeries and injections) and to medications of many different types, psychosocial interventions and skill training are an important aspect in the treatment of chronic pain conditions.

Chronic pain is a bio-psychosocial condition in which psychological factors play a critical role. An analysis of the literature on low back pain finds that several behavioral therapies (operant, respondent, and cognitive) are effective in reducing the disability of low back pain [2]. Cognitive behavioral treatment has been shown to be effective in treating jaw pain [3]. Multidisciplinary pain treatment (MDPT) has been shown to be highly effective in the treatment of chronic pain conditions $[4,5]$. The impact of MDPT appears to be highly mediated by a patient's catastrophizing [6], which has been shown to be a key variable in producing successful outcomes in treatments for chronic pain [7]. However, the problem for pain practitioners usually is having access to skilled pain psychotherapists and the resources that MDPT requires so that these services can be offered to patients. In addition, many factors also play a part in patient attendance and participation in MDPT sessions, as transportation, motivation, multiple responsibilities, and other environmental problems all can play a role in keeping patients from attending sessions.

Single session interventions have been shown to be effective and helpful in other areas of mental health and pain treatment. Wong et al. [8] demonstrated that a 30-min educational intervention decreased post-surgical pain and anxiety. Similar positive results have been reported in single session treatments of dental phobia [9], specific phobia [10], substance abuse [11], traumatic memories [12], vulvodynia [13], and a variety of mental health disorders [14]. The present study presents the results of offering some key aspects of the MDPT model to chronic pain patients in a single session model. If successful, this would offer a cost-effective way in which more healthcare practitioners could offer an important service that decreases patient catastrophizing and may improve outcomes in chronic pain treatment.

One issue that quickly arises in planning a single session group intervention is what skill(s) to teach. Studies have shown that cognitive-behavioral therapy (CBT) skills [15], patient education [7], relaxation, and selfregulation [16] all have been helpful in the general treatment of chronic pain. Popular books for professionals about the treatment of chronic pain review a number of helpful skills that benefit patients. Turk and Winter [17] described the skills of understanding chronic pain, appropriate activity cycles, relaxation, coping with fatigue, communication, helpful thinking, and problem solving. Thorn [18] offered materials and described a ten-session structured group intervention focusing on CBT skills. Jamison [19] discussed the importance of addressing chronic pain, relaxation, exercise, posture, stress management, sleep hygiene, "comfort measures," helpful thinking, vocational rehabilitation, sexual issues, weight management, humor, and social support. Caudill [20] discussed interventions in the areas of understanding chronic pain, relaxation, time management, nutrition, helpful thinking, communication, and problem-solving. Thus, designing a single 
session intervention requires some decisionmaking about what skill or skills to teach in a limited time.

After a review of several books on coping with chronic pain (cited above) and based on the authors' clinical experience, the authors created a theoretical model that posits five key skills that pain patients should have if they are to successfully manage their pain. These skills, named for easy patient reference, are understanding, accepting, calming, balancing, and coping. In addition to being referenced by clinicians in the books about chronic pain, each of these skills has empirical support for its inclusion in a group of patients with chronic pain (understanding and education [7, 21, 22], accepting and CBT [15], calming and relaxation [16], balancing and activity pacing [12], coping and distraction [23]). The authors' 120-min, single group session addressed each of these areas, albeit briefly. In this way, patients were given a short but comprehensive introduction to dealing with chronic pain rather than focusing on any one particular single skill area. A more detailed outline of the group session is offered in Fig. 1, and each major section of the group is discussed below.

Understanding refers to a patient having some basic knowledge about their pain condition, common treatments available, and how pain works in general. In particular, understanding how the mind and body interact through the concept of "pain gates" [24] seems to the authors to validate for the patient that psychological interventions are an important part of overall pain treatment. Accepting refers to traditional cognitivebehavioral concepts and the importance of a patient's attitude towards his or her pain condition in successfully managing one's pain. In this area, the authors distinguish pain and suffering so patients may begin to understand

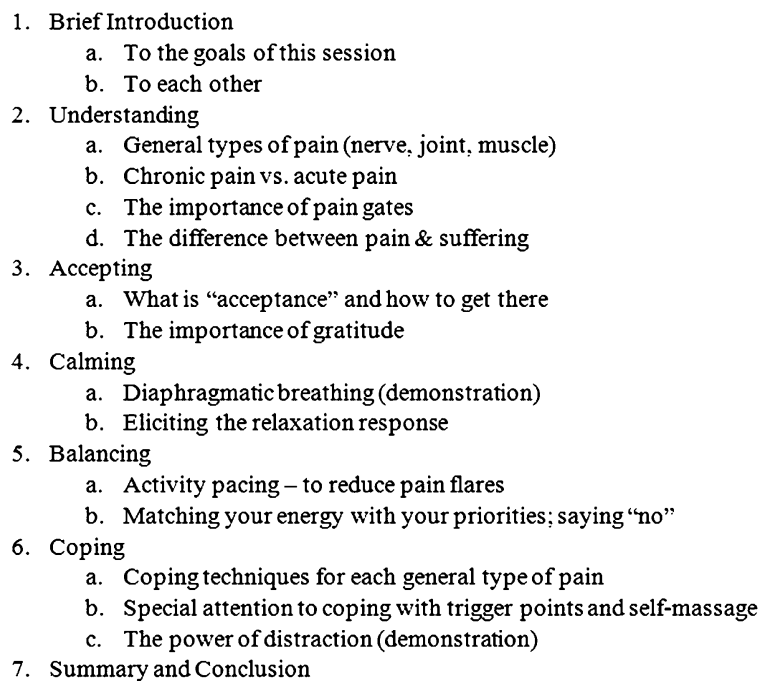

Fig. 1 Single group session outline

that having pain does not mandate emotional suffering. Calming refers to the importance of patients having stress management skills, building on the understanding area discussed earlier in group wherein it is noted how stress makes any pain condition worse. Relaxation encompasses a subset of skills within this calming area. Balancing refers to several issues faced by patients with chronic pain that involve the importance of life balance in a pain patient's life. Sleep hygiene, assertiveness, and "shoulds versus wants" also fall in this category, but the major focus in the authors' group is on activity pacing and not overdoing physical activities in a way that causes repeated pain flares. The final area of attention in the group is coping. Pain coping is sometimes neglected in the professional literature (though Jamison [19] does discuss it as "comfort measures"), but the authors' clinical experience has shown that this is a very important skill set. Patients need ways to decrease the intensity of pain, particularly during pain flares, without resorting to abuse of pain medication; therefore, simple techniques using heat, ice, and over-the-counter creams are discussed. Special attention is given to 
self-massage for myofascial trigger points. In addition, distraction is highlighted as a very effective means of decreasing pain. In the authors' experience, a brief review of these fairly simple pain coping and pain reduction techniques can give a patient necessary hope and confidence that he or she has the tools to "get by" in times of increased pain.

In sum, the current pilot study was designed to explore the helpfulness of a single group session for patients with a variety of chronic pain disorders. The single session group, $120 \mathrm{~min}$ in length, addressed the five skills areas thought to be important in dealing with chronic pain: understanding, accepting, calming, balancing, and coping. The hypothesis tested was that a single session group would be an effective intervention to decrease patient catastrophizing, a primary mediator of patient outcomes in pain treatment.

\section{METHODS}

The subjects of this study were patients at a pain practice in Knoxville, TN, USA. All new patients at the practice met with the psychologist for assessment, and in this initial session the patients were informed of this single session group offering. A few new patients were not educated about the group due to significant mental health or mental status issues (severe mental illness, mental retardation, dementia and the like) that made the likelihood of benefitting from a group session unlikely. The number of patients excluded is estimated as a total of five. Otherwise, this group offering was mentioned to all patients new to the practice. In addition, medical staff referred some longstanding patients to the group when it appeared that the patients were in need of additional coping skills to deal with their pain.
The session lasted $120 \mathrm{~min}$ and was held twice a month in a small unused waiting area (the only available space that could accommodate a group). Patients were not mandated to be there by medical staff (e.g., had to attend in order to receive medication) and, thus, were all voluntary and self-selected. The average group size was three to four patients. The session started with a brief overview of the rationale for the class followed by personal introductions. This allowed patients time to briefly share their stories with each other, another important aspect of having a pain group. The authors then spent roughly $20 \mathrm{~min}$ on each of the five skill areas mentioned previously: understanding, accepting, calming, balancing, and coping. There was an emphasis on practical skill training and experiential learning. Brief exercises were conducted on diaphragmatic breathing and distraction as a pain coping tool. Material was presented in a didactic manner, but care was taken to communicate at an appropriate level to ensure information was successfully relayed. Single page handouts on the topics were distributed to patients for future reference. An outline of the group session is presented in Fig. 1.

A primary dependent variable for the present study was pain catastrophizing. As noted earlier, catastrophizing has been shown to be a predictor of pain intensity, disability, and psychological distress independent of physical impairment [25]. In fact, it appears that patient catastrophizing is the primary mediator in the reduction of disability and pain intensity for any type of effective pain treatment program [26]. To measure catastrophizing, the Pain Catastrophizing Scale (PCS) was used [27]. While there are many scales that measure the important construct of pain catastrophizing, this 13-item scale has received the most attention in the literature. The PCS "has taken 
a prominent position (in the proliferation of psychosocial pain scales) because of its strong relationship to ratings of the experience of pain, as well as adjustment to chronic pain" [17, p. 59]. Thus, the PCS was chosen to be a primary outcome measure of the impact of the group session.

After a pre-intervention assessment, the session was conducted without a break (patients were allowed to stand, move, and stretch as needed during group). At the end of the session, the patients filled out two Likert scale rating items about the class, the PCS, and they were given a chance to offer general written feedback about the class. Approximately 3 months after session completion patients were given, at their regularly scheduled medical appointment, an inventory using the same items as in the postsession evaluation, which included the PCS. If the patient did not have an appointment or had dropped out of treatment for some reason, the inventory was mailed to them with a selfaddressed stamped envelope with which to return the forms. No patient attended the group session more than once. All procedures followed were in accordance with the ethical standards of the responsible committee on human experimentation (institutional and national) and with the Helsinki Declaration of 1975 , as revised in 2000. Informed consent was obtained from all patients for being included in the study.

\section{Statistical Analysis}

The hypothesis was tested that a single psychoeducational group session would significantly reduce unhelpful thinking about pain as measured by the PCS at 3-month follow-up utilizing the statistical program SPSS version 20 (IBM Corp. Armonk, NY: IBM Corp).
Age was found to be a confounding variable and was controlled for in all analyses. The authors examined overall PCS scores as well as the three subscales that comprise the scale with $t$ tests using the $P$ value of 0.05 to measure significance. Second, analyses were conducted to examine whether the group of people who did not complete the follow-up questionnaire significantly differed from those that completed all aspects of the study. Effect sizes were also calculated to further examine differences between pain scores from baseline to follow-up.

\section{RESULTS}

The sample was originally composed of 78 participants. Of these, 25 participants were excluded from the analyses for not completing the post-intervention data, leaving a final sample of 53 participants. Age of the participants ranged from 21 to 76 with a mean age of 49.43 (SD 11.08). Approximately $70 \%$ of the sample were females $(n=37)$. The majority of the sample reported their current marital status as married (70\%), with 13\% reporting being single, 13\% divorced, and 4\% widowed. Of the sample, $64 \%$ reported the primary location of their pain as lumbar, 9\% cervical, $8 \%$ all over, and other pain sites making up the rest. Results showed that location of pain, marital status, and gender did not significantly differ between the groups. Age, however, was a factor in whether patients completed the post data collection $[t(76)=2.20, P=0.03]$, in that older people were significantly less likely to complete follow-up data collection than younger participants. As a result, age was entered as a covariate in the following analyses.

Overall pain scores significantly decreased between baseline [mean $(M)=28.09$, SD 10.97] and follow-up $(M=24.72$, SD 13.22), 
$t(52)=2.35, P<0.05 \quad$ (effect size $d=0.28$ ). Significant decreases were found for two of the three subscales on the PCS. The Rumination subscale significantly differed from the pre- to post-PCS $[t(52)=2.14, P=0.037)$, as did the Helplessness subscale [ $t(52)=2.44, P=0.018$ ] The Magnification subscale was not significantly different at follow-up from baseline.

Of the 53 patients who completed follow-up questionnaires, $100 \%$ of them reported remembering the group session administered 3 months prior. Moreover, over half of patients reported that the group helped a great deal (53\%). A total of $43 \%$ of patients felt the group "helped a little" and only 4\% believed the group "did not seem to help at all." Patient responses to two four-point Likert rating items administered after the group revealed that $83 \%$ of participants would recommend the group to others with chronic pain, with 9\% saying they would "probably" recommend the group, $2 \%$ reporting they would "maybe" recommend, and $6 \%$ of patients not responding. At the 3-month follow-up, $85 \%$ of patients agreed they would recommend the group to others struggling with chronic pain (55\% would "definitely" and 30\% would "probably" recommend). The remaining 15\% of respondents said they would "maybe" recommend the group with no patients saying they would not recommend the group. Patients were asked to write down what was most helpful to them from the group session. These answers were categorized and tabulated. A total of $34 \%$ reported pacing or slowing down was the most helpful skill learned, followed by coping techniques to deal with pain (17\%), learning new thinking about pain (11\%), and relaxation (6\%). At 3-month follow-up, patients reported general pain coping techniques as the most helpful piece of information garnered from group participation (23\%). Other helpful tools learned included general information (21\%), discussion with others, "knowing I'm not alone" and being in a group format (19\%), and relaxation (12\%).

Written comments about the group revealed the value that the patients found in this group session. Written comments included the following: "The class was great-learned a few new things", "This was very insightful as to have coping and/or managing with my pain" [sic], "It helps to hear from other people about their pain and how they deal with it", "Wish I would have taken it years ago. I have been through all the emotions dealing with disability. It would be excellent for new patients", "Handouts will be helpful for my flare management pain-wish I'd had this 2 years ago", and "I believe any doctor's office prescribing any pain medications should by law require classes such as this. People with chronic pain have the right to be educated as to options we have to not only pain medication but pain education."

\section{DISCUSSION}

The data gathered here suggest that a single group session of $120 \mathrm{~min}$ can have a significant positive impact on chronic pain patients. Introducing patients to five key skills-understanding, accepting, calming, balancing, and coping-was shown here to reduce pain catastrophizing at 3-month follow-up. Analysis of the three subscales of the PCS finds that even though patients may have continued to magnify their pain levels, they felt less helpless and ruminated less on the pain following the single group session. A clear majority of patients, both immediately after group and at 3-month follow-up, rated the group as helpful and recommended it for 
other pain patients. Patients indicated that they found various aspects of the group helpful. Written comments also touted the value of the group, particularly for patients new to chronic pain.

This study should be seen as a pilot study due to its small sample size and limited patient demographic information that could help better understand the findings and what factors may impact the significance of the single group session (i.e., education level, psychopathology, duration of pain). While hopeful in its findings, a larger study sample is needed to confirm the value of this group. Additionally, in subsequent replication studies, participants should be assessed at 6-, 9-, and/or 12-month follow-up intervals with several diverse outcome measures to truly determine the long-term impact of the session on catastrophizing and pain management in general. A control group would have lent further validity to the study. However, because the present study was conducted at a small outpatient pain clinic as part of standard clinical practice, randomization and a large sample size was not feasible. The authors look forward to future studies that would use a control group in assessing this single session intervention. Research in other patient populations in other areas of the country is also called for to confirm that this model is generalizable and helpful to others outside of this clinic's population.

\section{CONCLUSION}

This study offers pain clinicians a potential new tool in addressing the needs of chronic pain patients. The 120-min session is not highly sophisticated in its teaching techniques and, in the authors' view, need not necessarily be conducted by a licensed clinical psychologist. The authors think the basic education and skill training needed to offer this group is something any number of healthcare providers could offer, should they choose to do so. The single session format also offers an alternative to traditional psychology or psychoeducational groups, which are usually offered in 8-12 week formats. In the authors' population, many patients have various obstacles to attending weekly groups. This single session format could offer an innovative way to impart helpful information in a cost-efficient manner to decrease pain catastrophizing.

\section{ACKNOWLEDGMENTS}

No funding or sponsorship was received for this study or publication of the article. Dr. Jones is the guarantor for this article, and takes responsibility for the integrity of the work as a whole.

Conflict of interest. All authors declare no conflict of interest.

Open Access. This article is distributed under the terms of the Creative Commons Attribution Noncommercial License which permits any noncommercial use, distribution, and reproduction in any medium, provided the original author(s) and the source are credited.

\section{REFERENCES}

1. Institute of Medicine (IOM). Relieving pain in America: a blueprint for transforming prevention, care, education, and research. Washington, DC: The National Academies Press; 2011.

2. Henscke N, Ostelo RW, van Tulder MW, Vlaeyen JW, Morley S, Assendelf WJ, Main CJ. Behavioral 
treatment for chronic low-back pain. Cochrane Database Syst Rev. 2010;7:DC002014.

3. Litt MD, Shafer DM, Kreutzer DL. Brief cognitivebehavioral treatment for TMD pain: long-term outcomes and moderators of treatment. Pain. 2010;151:110-6.

4. Dysvik E, Kvaloy JT, Stokkeland R, Natvig GK. The effectiveness of a multidisciplinary pain management programme managing chronic pain on pain perceptions, health-related quality of life and stages of change-a non-randomized controlled study. Int J Nurs Stud. 2010;47:826-35.

5. Jensen MP, Turner JA, Romano JM. Changes after multidisciplinary pain treatment in patient pain beliefs and coping are associated with concurrent changes in patient functioning. Pain. 2007;131:38-47.

6. Jensen MP, Turner JA, Romano JM. Changes in beliefs, catastrophizing, and coping are associated with improvement in multidisciplinary pain treatment. J Consult Clin Psychol. 2001;69:655-62.

7. Quartana PJ, Campbell CM, Edwards RR. Pain catastrophizing: a critical review. Expert Rev Neurother. 2009;9:745-58.

8. Wong EM, Chan SW, Chair SY. Effectiveness of an educational intervention on levels of pain, anxiety, and self-efficacy for patients with musculoskeletal trauma. J Adv Nurs. 2010;66:1120-31.

9. Thom A, Sartory G, Johren P. Comparison between one-session psychological treatment and benzodiazepines in dental phobia. J Consult Clin Psychol. 2000;68:378-87.

10. Zlomke K, Davis TE 3rd. One-session treatment of specific phobia: a detailed description and review of treatment efficacy. Behav Ther. 2008;39:207-23.

11. Rubak S, Sandbaek A, Lauritzen T, Christensen B. Motivational interviewing: a systematic review and meta-analysis. Br J Gen Pract. 2005;55:305-12.

12. Church D, Pina O, Reategui C, Brooks A. Single session reduction of the intensity of traumatic memories in abused adolescents: a randomized controlled trial. Traumatology. 2012;18:73-9.

13. Moravek MB. Single counseling session may help vulvodynia. In: Presented at annual meeting of the American College of Obstetricians and Gynecologists, New York, October 19, 2012.

14. Rockwell WK, Pinkerton RS. Single session psychotherapy. Am J Psychother. 1982;36:32-40.

15. Morley S, Eccleston C, Williams A. Systematic review and meta-analysis of randomized controlled trials of cognitive behavioral therapy and behavior therapy for chronic pain in adults, excluding headache. Pain. 1999;80:1-13.

16. Sauer SE, Burris JL, Carlson CR. New directions in the management of chronic pain: self-regulation theory as a model for integrative clinical psychology practice. Clin Psychol Rev. 2010;30: 805-14.

17. Turk DC, Winter F. The pain survival guide: how to reclaim your life. Washington, DC: The American Psychological Association; 2006.

18. Thorn BE. Cognitive therapy for chronic pain: a step-by-step guide. New York: The Guilford Press; 2004.

19. Jamison RN. Learning to master your chronic pain. Sarasota: Professional Resource Press; 1996.

20. Caudill MA. Managing pain before it manages you. New York: The Guilford Press; 1995.

21. Carnes D, Taylor SJC, Homer K, et al. Effectiveness and cost-effectiveness of a novel, group selfmanagement course for adults with chronic musculoskeletal pain: study protocol for a multicenter, randomized controlled trial (COPERS). BMJ Open. 2013;3. pii: e002492.

22. Friedberg FG, Williams DA, Collinge W. Lifestyleoriented non-pharmacological treatment for fibromyalgia: a clinical overview and applications with home-based technologies. J Pain Res. 2012;5: 425-35.

23. Jameson E, Trevena J, Swain N. Electronic gaming as pain distraction. Pain Res Manag. 2011;16:27-32.

24. Melzack R, Wall PD. Pain mechanisms: a new theory. Science. 1965;150:971-9.

25. Severeijns R, Vlaeyen JWS, van den Hout MA, Weber WEJ. Pain catastrophizing predicts pain intensity, disability, and psychological distress independent of the level of physical impairment. Clin J Pain. 2001;17:165-72.

26. Smeets RJEM, Vlaeyen JWS, Kester ADM, et al. Reduction of pain catastrophizing mediates the outcome of both physical and cognitive-behavioral treatment in chronic low back pain. J Pain. 2006;7:261-71.

27. Sullivan MJL, Bishop S, Pivik J. The pain catastrophizing scale: development and validation. Psychol Assess. 1995;7:524-32. 